\title{
Exploring the Influence of Context on Attitudes toward Web-Based Learning Tools (WBLTs) and Learning Performance
}

\author{
Robin Kay \\ University of Ontario Institute of Technology, \\ Oshawa, Ontario, Canada
}

\author{
robin.kay@uoit.ca
}

\begin{abstract}
The purpose of this study was to explore the influence of context on student attitudes toward Web-Based Learning Tools (WBLTs) and learning performance. Survey data about attitudes and quasi-experimental data on learning performance were collected from 832 middle and secondary schools students. Five contextual variables were assessed including subject area (math vs. science), grade level (middle vs. secondary school), lesson plan format (teacher led vs. student based), collaboration (pairs vs. individual), and technological problems experienced (minor vs. major). Science-based WBLTs, higher grade levels, teacher-led lessons, and the absence of major technological problems were associated with significantly higher student attitudes toward the learning, design, and engagement value of WBLTs. Science-based WBLTs, higher grade levels, teacher-led lessons, working alone, and the absence of software problems were associated with significant gains in student learning performance. It is reasonable to conclude that the context in which a WBLT is taught can significantly influence student attitudes and learning performance.
\end{abstract}

Keywords: evaluate, strategies, assess, quality, middle school, secondary school, high school, learning object, web-based learning tools, math, science, collaboration

\section{Introduction}

Web-Based Learning Tools (WBLTs), also referred to as learning objects, are operationally defined in this study as "interactive web-based tools that support the learning of specific concepts by enhancing, amplifying, and/or guiding the cognitive processes of learners." This definition is derived from previous attempts to delineate critical features of learning objects (Kay \& Knaack, 2008a; 2009). The WBLTs used in this study enabled students to explore, manipulate variables, apply concepts, or answer questions based on formal presentation of material targeting a relatively narrow concept.

Material published as part of this publication, either on-line or in print, is copyrighted by the Informing Science Institute. Permission to make digital or paper copy of part or all of these works for personal or classroom use is granted without fee provided that the copies are not made or distributed for profit or commercial advantage AND that copies 1) bear this notice in full and 2) give the full citation on the first page. It is permissible to abstract these works so long as credit is given. To copy in all other cases or to republish or to post on a server or to redistribute to lists requires specific permission and payment of a fee. Contact Publisher@InformingScience.org to request redistribution permission.
Research over the past 10 years suggests that, overall, WBLTs have had a positive effect on student attitudes and learning performance (e.g., Akpinar \& Bal, 2006; Docherty, Hoy, Topp, \& Trinder, 2005; Kay \& Knaack, 2007a, 2007b; Lim, Lee, \& Richards, 2006; Nurmi \& Jaakkola, 2006). A closer look at the data, though, reveals that WBLTs are not always accepted or beneficial. Student attitudes toward WBLTs and im- 
pact on learning performance vary according to teaching strategies used and individual characteristics of students. For example, teaching approach (e.g., coaching, scaffolding, preparation) can influence the impact of a WBLT (Kay, Knaack, \& Muirhead, 2009; Liu \& Bera, 2005; Schoner, Buzza, Harrigan, \& Strampel, 2005; Van Marrienboer \& Ayres, 2005). In addtion, attributes such as gender, age, and computer comfort level affect student attitudes toward WBLTs and learning performance (De Salas \& Ellis, 2006; Lim et al., 2006; Kay \& Knaack, 2007b, 2008a, 2009).

One area, not yet studied in the domain of WBLTs, is the impact of learning context. According to Bransford, Brown, \& Cocking's (2000) seminal work, "Learning is influenced in fundamental ways by the context in which it takes place" (p. 25). Contextual factors such as the degree of collaboration, passive vs. active lesson plan design, and the impact of technology-based problems during a lesson have not been explored to date. The purpose of the following study was to examine the influence of contextual variables on student attitudes toward WBLTs and learning performance.

\section{Context and WBLTs}

While the effect of contextual variables has not been formally evaluated, an informal content analysis of 183 peer-reviewed articles (Kay, 2009) revealed five potentially important contextbased factors including subject area, grade level, lesson plan format, collaboration, and technology-based problems.

\section{Subject area}

The majority of WBLT research in middle and secondary school environments has focused on either mathematics or science (e.g., Akpinar \& Bal, 2006; Kay \& Knaack, 2007b, 2008; Kong \& Kwok, 2005; Liu \& Bera, 2005; Nurmi \& Jaakkola, 2006). Only one study has directly looked at the impact of subject area and WBLTs. Kay \& Knaack (2008b) reported that secondary school students rated science-based WBLTs significantly higher than math-based WBLTs with respect to learning, design, and engagement. In addition, learning performance was significantly higher when science-based WBLTs were used. Kay \& Knaack (2008b) were at a loss to explain why the difference occurred but speculated that science-based WBLTs may focus on concepts that are more concrete, visual, and easier for students to relate to than abstract mathematical ideas that have less real-world application. It is possible that WBLTs are better suited to concepts that have a personally meaningful context. Bransford et al.'s (2000) comprehensive analysis of how people learn suggests that establishing context and meaning for concepts, as opposed to teaching disconnected facts, is critical for student success. More research is needed to confirm whether subject area influences student attitudes and learning performance with respect to WBLTs.

\section{Grade level}

Research on grade level and the use of technology suggests that students in higher grades view computers as tools for getting work done (e.g., word processing, programming, use of the Internet, and email), whereas students in lower grades tend to see computers as a source of entertainment (e.g., play games and use graphics software) (Colley, 2003; Colley \& Comber, 2001; Comber, Colley, Hargreaves, \& Dorn, 1997). Regarding WBLTs, Kay \& Knaack (2007b, 2008a) reported that older students (Grade 12) were more positive about WBLTs and performed better than younger students (grade 9 and 10). De Salas \& Ellis (2006) added that second and third year university students were far more open to using WBLTs than first year students. WBLTs were originally created for higher education students (Haughey \& Muirhead, 2005), and it is possible that the range of cognitive skills required to use a WBLT (e.g., reading instructions, writing down results, interpreting and digesting "what-if" scenarios, working independently) may overwhelm 
younger students who are expecting to be entertained. More research is needed to determine whether the effect of grade level on attitudes toward WBLTs and learning performance is robust.

\section{Lesson plan format}

Considerable debate exists about the optimum level of instructional guidance necessary for successful learning (Kirschner, Sweller, \& Clark, 2006). Some researchers suggest that learning is best supported when students are given the essential tools and required to construct understanding themselves (e.g., Bruner, 1986; Steffe \& Gale, 1995; Vannatta \& Beyerbach, 2000; Vygotsky, 1978). This minimal level of instructional guidance is referred to by a variety of names including discovery learning, problem-based learning, inquiry learning, and constructivist learning (Kirschner et al., 2006). Other researchers maintain that students need to be provided with direct instruction to learn effectively (e.g., Cronbach \& Snow, 1977; Mayer, 2004; Sweller, 1988).

The constructivist approach has grown in popularity over the past 10 years; however Kirschner et al. (2006) provide considerable evidence to suggest that direct instruction is significantly more effective, particularly when students have limited knowledge and understanding of the concepts to be learned. To date, the role of the student and teacher in using WBLTs has not been examined. While WBLTs were designed for higher education students to work independently (e.g., Haughey \& Muirhead, 2005), it is unclear whether middle and/or secondary students learn best with a teacher-led as opposed to a student-based approach. If constructivist theorists are correct (e.g., Bruner, 1986; Papert, 1980; Vygotsky, 1978), a student-based approach should result in more effective learning. However, if Kirschner et al.'s (2006) analysis is accurate, a teacher-led WBLT lesson plan would probably work best.

\section{Collaboration}

While access to computers and the Internet in schools has increased markedly in the past ten years (Compton \& Harwood, 2003; Organization for Economic Co-operation and Development [OECD], 2006), average student-to-computer ratios range from 3:1 in the United States, 4:1 in Australia, 5:1 in Canada and England, and 10:1 in many European Countries (OECD, 2006). Therefore, students may have to share computers and collaborate when using WBLTs. The benefits of collaborative learning are well documented (e.g., Johnson \& Johnson, 1994, 1998; Kagan, 1997; Sharon, 1999); however, five key elements are necessary to ensure success and include positive interdependence, face-to-face interaction, individual accountability, social skills, and group processing (Johnson \& Johnson, 1994). Limited research has been conducted on the effect of collaboration and the use of WBLTs. One study examining individual vs. pairs use of WBLTs, reported that collaboration was not significantly related to student attitudes toward WBLTS or student performance (Kay, Knaack, \& Muirhead, 2009). More research is needed to investigate the role of collaboration and the use of WBLTs.

\section{Technology problems}

Numerous challenges have been documented regarding teachers' use of technology in the classroom and include excessive time required to learn new software (Eifler, Greene, \& Carroll, 2001; Wepner, Ziomek, \& Tao, 2003), fear and anxiety associated with using technology (Bullock, 2004; Doering, Hughes, \& Huffman., 2003), limited technological skills (Eifler et al., 2001; Strudler and Wetzel, 1999; and insufficient access to software and hardware (Bartlett, 2002; Russell, Bebell, O'Dwyer, \& O'Connor, 2003). Less has been written about the impact of technological challenges on student attitudes and learning during an actual lesson. One study noted that $60 \%$ of teachers experienced some level of software or hardware-based problems while WBLTs were being used (Kay, Knaack, \& Petrarca, 2009). No studies have examined the extent to which hardware and software problems alter the learning experience associated with using WBLTs. 
Because the use of WBLTs is partially dependent on computers that work well and software that runs smoothly, it is important to examine both the frequency and magnitude of difficulties observed.

\section{Purpose}

The purpose of the current study was to examine the influence of five context-based variables on student attitudes toward WBLTs and learning performance. The context-based variables assessed included subject area (math vs. science), grade level (middle vs. secondary school), lesson plan format (teacher vs. student based), collaboration (pairs vs. individual), and technology problems (minor vs. major).

\section{Method}

\section{Overview}

Six key steps were followed in this study, based on Kay \& Knaack's (2009) extensive review of WBLT research, to ensure high quality of data collection and analysis. These include using:

1. a large number of WBLTs;

2. a sizeable, diverse, sample;

3. reliable and valid measurement tools;

4. a database of carefully pre-selected WBLTs;

5. pre-designed lesson plans created by experienced teachers; and

6. an enhanced measure of learning performance custom designed for each WBLT .

\section{Sample}

\section{Students}

The sample student population consisted of middle ( $\mathrm{n}=442$, 244 females, 198 males) and secondary $(\mathrm{n}=390,197$ females, 193 male) school students ranging from 11 to 17 years of age $(M=$ 13.3, $S D=0.97)$. Students were enrolled in grades seven $(n=228)$, eight $(n=214)$, nine $(n=348)$, or ten $(n=43)$. Seventy-six percent $(n=627)$ of the students reported that their average mark was $70 \%$ or more in the subject area where the WBLT was used. In addition, over $75 \%$ of the students agreed or strongly agreed that they were comfortable at working with computers in school. Students were sampled from 33 different classes located in a sub-urban region of nearly 600,000 people.

\section{Teachers}

The sample teacher population included 28 teachers ( 8 males, 20 females) who taught mathematics $(n=15)$ or science $(n=13)$ in grades seven $(n=9)$, eight $(n=9)$, nine $(n=7)$ or ten $(n=2)$. Class size ranged from 9 to 28 with a mean of 18 students $(S D=5.4)$. Teaching experience varied from 0.5 to 23 years with a mean of $7.1(S D=6.7)$. Twenty-three out of 28 teachers agreed that they were good at and liked working with computers.

\section{WBLT selection and lesson plan design}

Four teachers were hired and trained for two days on how to select WBLTs and develop effective lesson plans. WBLTs were chosen based on Kay \& Knaack's (2008b) multi-component model for assessing WBLTs. Lessons plan design was based on previous research identifying successful teaching strategies for using WBLTs (Kay, Knaack, \& Muirhead, 2009). Key dimensions of a good quality lesson plan included a guiding set of questions, a structured well-organized plan for 
using a WBLT, and time to consolidate concepts learned. Lessons were 70 minutes in duration and comprised of an introduction (10 min.), guiding questions and activities involving the use of a WBLT (50 minutes), and consolidation (10 min).

A database of 122 lesson plans and WBLTs was created over a period of two months (78 for mathematics and 44 for science). Twenty-two unique WBLTs from this database were used by classroom teachers in this study. See Kay (2011) for links to all WBLTs, corresponding lesson plans, and pre-post tests.

\section{Procedure}

Teachers from two boards of education were informed of the WBLT study by an educational coordinator. Participation was voluntary and teachers could withdraw at any time. Note that no teachers or students chose to withdraw from the study. Each participant received a full day of training on implementing the pre-designed WBLT lesson plans. After the training session, they were then asked to use at least one WBLT in their classroom in the following three months. Email support was available for duration of the study. All students in a given teacher's class participated in the WBLT lesson chosen by the teacher; however, survey and pre-post test data was only collected from those students with signed parental permission forms.

\section{Research Design and Data Sources}

\section{Overview}

A mixed methods research design was used in this study to assess the influence of five explanatory variables (subject area, grade level, lesson plan format, collaboration, and implementation problems) on two response variables (student attitudes and change in learning performance). Student attitude data was collected using an online survey and compared within each context variable. Change in learning performance was attained using a quasi-experimental approach where pre-test scores were subtracted from post-test scores. Change in learning performance was then compared within each context variable. Subjects were neither selected nor assigned randomly they volunteered to participate.

\section{Explanatory variables}

Five context-based explanatory variables were assessed including subject area, grade level, lesson plan format, collaboration, and implementation problems. Subject area was either math $(n=388)$ or science $(n=445)$. Grade level was either middle $(n=442)$ or secondary school $(n=391)$. Lesson plan format was either teacher-led $(n=227)$ where the instructor displayed the WBLT at the front of the class using an LCD projector or student-based where students worked in a computer lab $(n=582)$. Collaboration was assessed by comparing students working in pairs $(n=345)$ with those working individually $(n=176)$. Finally, technology-based problems were explored by comparing classes where no/minor problems existed with classes where major problems occurred in two areas: hardware and software.

\section{Response variables}

Two categories of response variables were used in this study: student attitudes toward WBLTs and learning performance. Student attitudes towards WBLTs were assessed using the WBLT Evaluation Scale for Students which consisted of 13, seven-point Likert scale items asking students about their perceptions of how much they had learned (learning construct - 5 items), the design of the WBLT (design construct - 4 items), and how much they were engaged when using the WBLT (engagement construct - 4 items). According to Kay \& Knaack (2009), the scale dis- 
played good internal reliability, construct validity, convergent validity, and predictive validity (see the Appendix for the scale items).

Learning performance was assessed by asking students to complete pre- and post-tests based on the content of the WBLT used in class. These tests were included with all pre-designed lesson plans to match the learning goals of the WBLT. The difference between pre- and post-test scores was used to determine changes in student performance on four possible knowledge areas including remembering, understanding, application, and analysis. One or more of these knowledge areas, derived from the revised Bloom's Taxonomy (Anderson \& Krathwhol, 2001), were assessed based on the learning goals of each specific WBLT lesson.

\section{Research Questions}

To investigate contextual differences and the effectiveness of WBLTs, the following questions were addressed in the data analysis:

1. Does subject area (math vs. science) have a significant impact on student attitudes toward WBLTs and learning performance?

2. Does grade level (middle vs. secondary school) have a significant impact on student attitudes toward WBLTs and learning performance?

3. Does lesson plan format (teacher-led vs. student based) have a significant impact on student attitudes toward WBLTs and learning performance?

4. Does collaboration (pairs vs. individual) have a significant impact on student attitudes toward WBLTs and learning performance?

5. Do technology-based problems (minor vs. major) have a significant impact on student attitudes toward WBLTs and learning performance?

\section{Results}

\section{Subject Area}

\section{Attitudes toward WBLTs}

A MANOVA was run for subject area (math vs. science) and the three student attitude constructs. Gender, age, computer comfort level, subject area comfort level, and average grade in subject area were entered as covariates to address the impact of potentially confounding variables. Hotelling's T was significant $(p<.001)$, so independent comparisons of WBLT quality constructs were conducted. Student ratings of learning value $(p<.001)$, design $(p<.001)$, and engagement $(p$ $<.001)$ for WBLTs were significantly higher in science than in mathematics. The effect sizes for these differences based on Cohen's d are considered moderate (Cohen, 1988, 1992) (Table 1).

\section{Learning performance}

While a MANOVA is generally considered a better test when assessing multiple response variables, each WBLT had a unique set of learning goals that never targeted all five of Bloom's knowledge categories. It would be unrealistic for any one WBLT to cover such a wide range of knowledge. A MANOVA needs all five knowledge categories to run; therefore, a series of ANCOVAs was used to compare science and mathematics-based WBLTs on the four learning performance measures. Gender, age, computer comfort level, subject area comfort level, and average grade in subject area were entered as covariates to address the impact of potentially confounding variables. 
Total learning performance (all four categories) was significantly higher when science-based WBLTs were used $(p<.001)$. The effective size for this difference was considered moderate according to Cohen $(1988,1992)$. Learning performance was significantly higher for the analysis knowledge area $(p<.005)$ when science was taught with WBLTs. The effect size for this difference based on Cohen's d is considered large (Cohen, 1988, 1992). Changes in remembering, understanding, and application knowledge areas showed no significant differences between science and mathematics (Table 1).

Table 1: Student Attitudes and Learning Performance as a Function of Subject Area

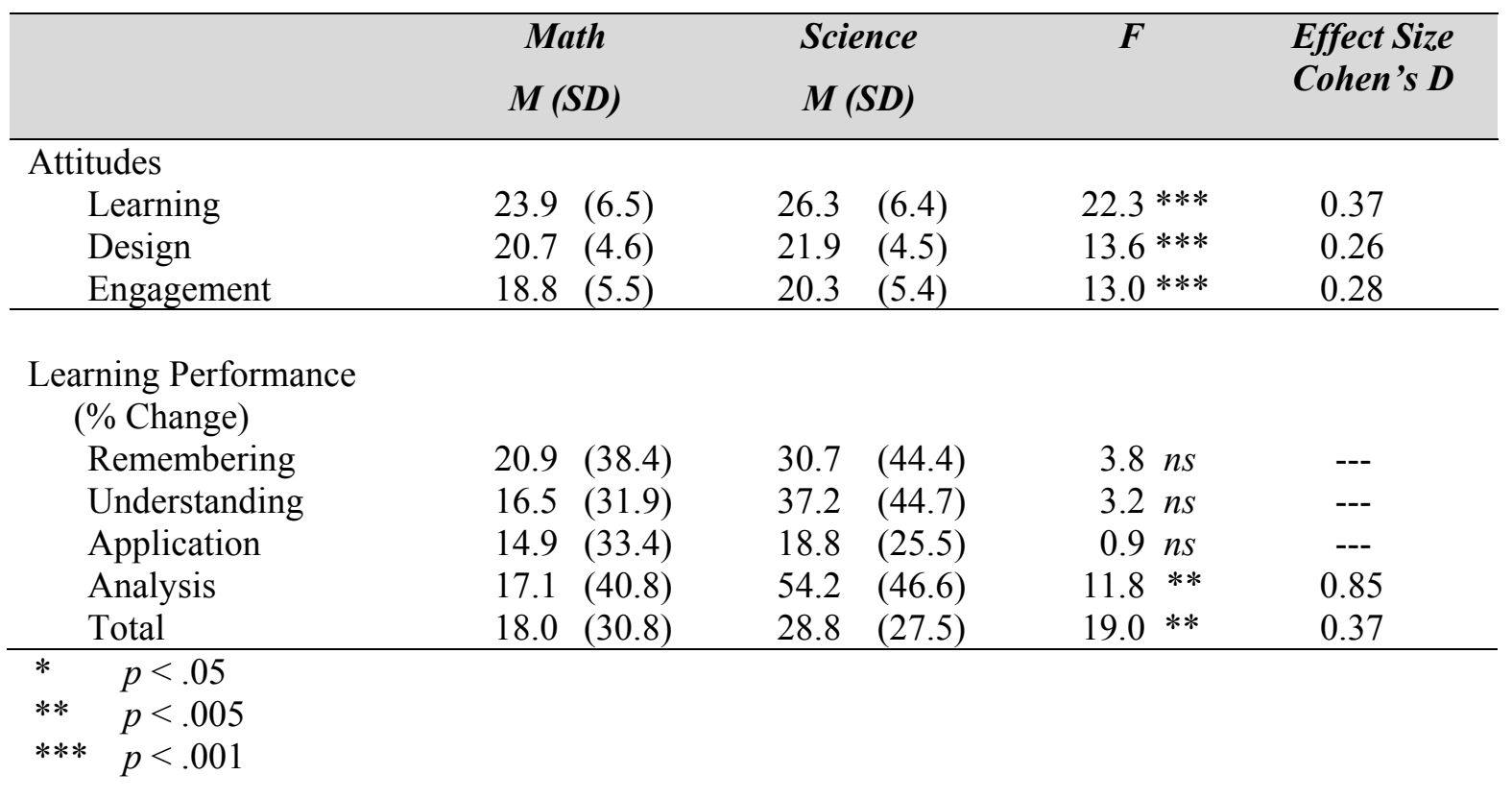

\section{Grade Level}

\section{Attitudes toward WBLTs}

A MANOVA was run for grade level (middle vs. secondary students) and the three student attitude constructs. Gender, computer comfort level, subject area comfort level, and average grade in subject area were entered as covariates. Hotelling's T was significant $(p<.001)$, so independent comparisons of WBLT quality constructs were conducted. Student ratings of learning value ( $p$ $<.001)$, design $(p<.001)$, and engagement $(p<.001)$ for WBLTs were significantly higher when WBLTs were used in secondary as opposed to middle school classrooms. The effect sizes for these differences based on Cohen's $d$ are considered small to moderate (Cohen, 1988, 1992) (Table 2).

\section{Learning performance}

A series of ANCOVAs were used to compare middle and secondary school use of WBLTs on the four learning performance measures. Gender, age, computer comfort level, subject area comfort level, and average grade in subject area were entered as covariates. Total learning performance (all four categories) was significantly higher when WBLTs were used by secondary students as opposed to middle school students $(p<.005)$. The effective size for this difference was considered large according to Cohen $(1988,1992)$. Changes in learning performance were significantly higher for remembering $(p<.001)$, understanding $(p<.005)$, application $(p<.001)$ and analysis $(p<.005)$ knowledge areas when WBLTs were used in secondary school classrooms. The effect 
sizes for these differences based on Cohen's d are considered moderate to large (Cohen, 1988, 1992) (Table 2).

Table 2: Student Attitudes and Learning Performance as a Function of Grade Level

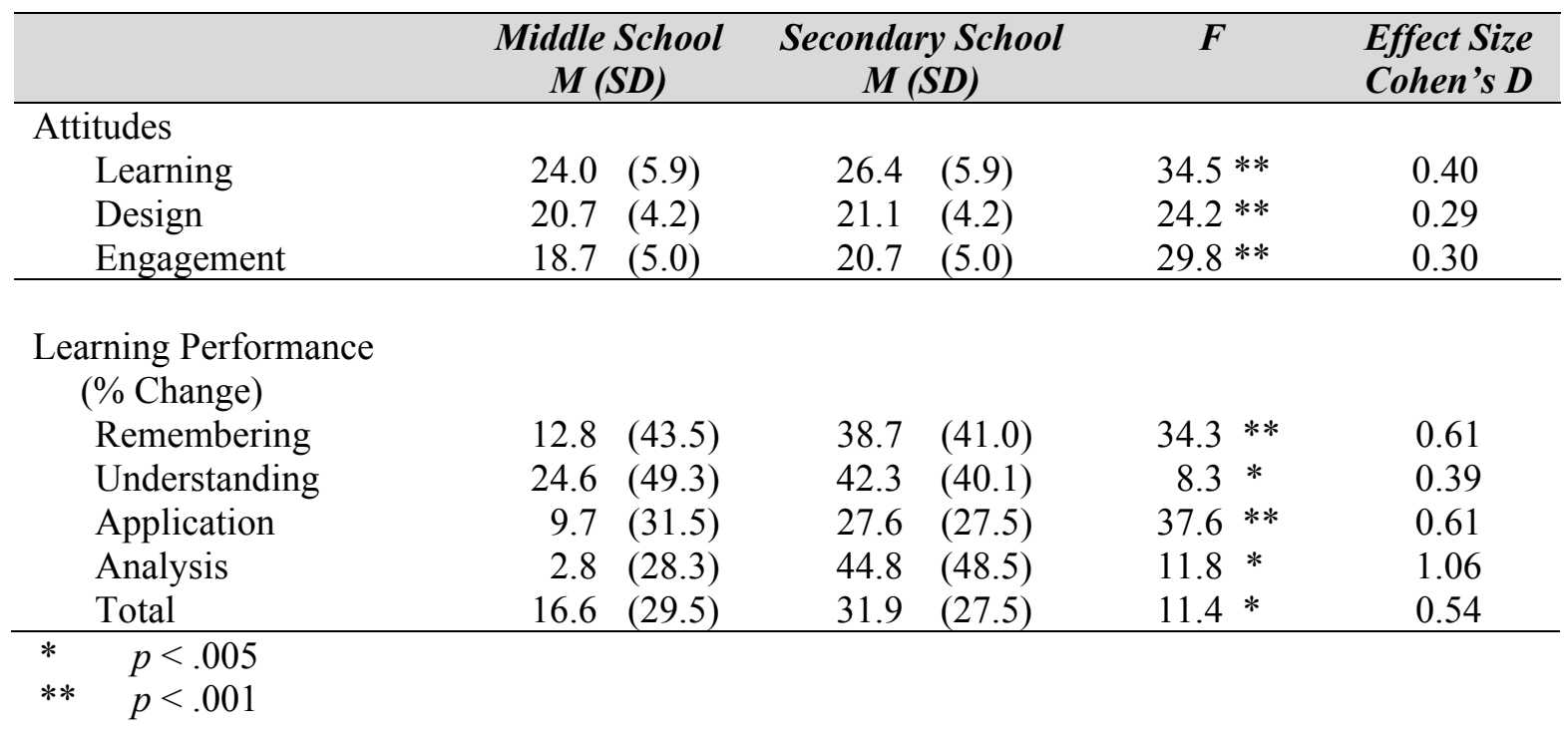

\section{Lesson Plan Format}

\section{Attitudes toward WBLTs}

A MANOVA was run for lesson plan format (teacher led vs. student-based) and the three student attitude constructs. Gender, age, computer comfort level, subject area comfort level, and average grade in subject area were entered as covariates. Hotelling's T was significant $(p<.001)$, so independent comparisons of WBLT quality constructs were conducted. Student ratings of learning value $(p<.001)$, design $(p<.001)$, and engagement $(p<.005)$ for WBLTs were significantly higher with a teacher-led lesson plan format. The effect sizes for these differences based on Cohen's $\mathrm{d}$ are considered small to moderate (Cohen, 1988, 1992) (Table 3).

\section{Learning performance and WBLTs}

A series of ANCOVAs were used to compare teacher-led and student-based WBLT lesson plan formats on the four learning performance measures. Gender, age, computer comfort level, subject area comfort level, and average grade in subject area were entered as covariates. Total learning performance (all four categories) was significantly higher when the WBLT lesson plan was teacher-led as opposed to student-based $(p<.001)$. The effective size for this difference was considered moderate according to Cohen $(1988,1992)$. Changes in learning performance were significantly higher for the understanding knowledge category $(p<.005)$ when a teacher-led lesson plan format was used. The effect size for this difference, based on Cohen's d, is considered large (Cohen, 1988, 1992). Changes in remembering, understanding and application knowledge areas showed no significant differences with respect to lesson plan format (Table 3). 
Table 3: Student Attitudes and Learning Performance as a Function of Lesson Plan Format

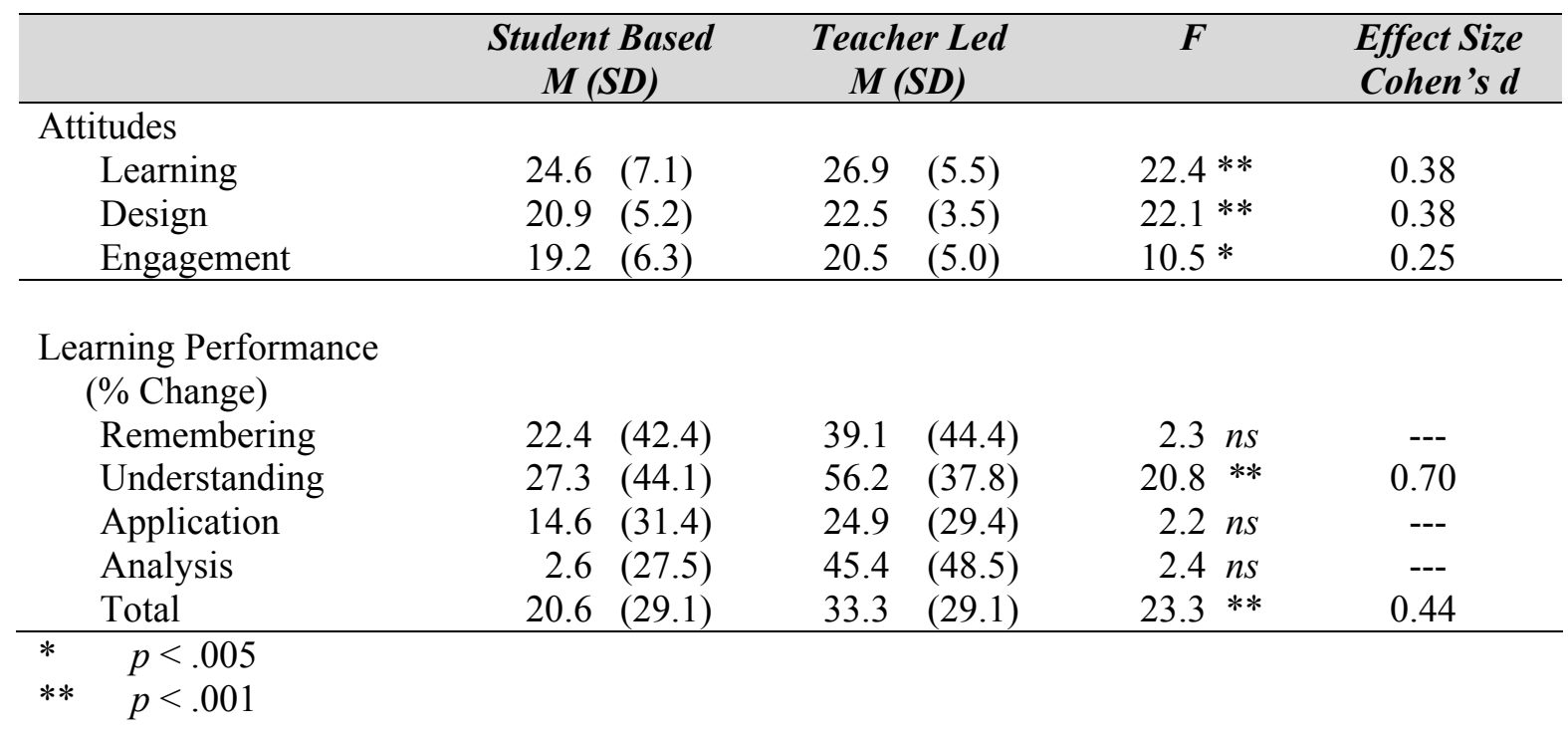

\section{Collaboration}

\section{Attitudes toward WBLTs}

A MANOVA was run for collaboration (individual vs. working in pairs) and the three student attitude constructs. Gender, age, computer comfort level, subject area comfort level, and average grade in subject area were entered as covariates. Hotelling's T was not significant, so it was concluded that there were no significant differences in student attitudes with respect to individual vs. pairs' use of WBLTs (Table 4).

Table 4: Student Attitudes and Learning Performance as a Function of Collaboration

\begin{tabular}{|c|c|c|c|c|}
\hline & $\begin{array}{l}\text { Individual } \\
\text { (M (SD) }\end{array}$ & $\begin{array}{c}\text { Pairs } \\
M(S D)\end{array}$ & $F$ & $\begin{array}{l}\text { Effect Size } \\
\text { Cohen's d }\end{array}$ \\
\hline \multicolumn{5}{|l|}{ Perceptions of } \\
\hline Learning & $25.7 \quad(6.0)$ & (5.9) & $1.3 n s$ & --- \\
\hline Design & $21.6 \quad(4.2)$ & (4.1) & $1.0 \mathrm{~ns}$ & --- \\
\hline Engagement & $19.6 \quad(5.3)$ & (5.3) & $0.1 n s$ & --- \\
\hline \multicolumn{5}{|c|}{$\begin{array}{l}\text { Learning Performance } \\
\qquad(\% \text { Change })\end{array}$} \\
\hline Remembering & $49.3 \quad(49.4)$ & $(37.4)$ & $18.3 * *$ & 0.76 \\
\hline Understanding & $35.7 \quad(41.0)$ & $(44.5)$ & $2.2 n s$ & --- \\
\hline Application & $20.0 \quad(29.8)$ & $(30.3)$ & $2.2 n s$ & --- \\
\hline Total & $27.1 \quad(31.7)$ & $(28.4)$ & $5.1 *$ & 0.24 \\
\hline
\end{tabular}

\section{Learning performance and WBLTs}

A series of ANCOVAs were used to compare individual vs. pair use of WBLTs on the four learning performance measures. Gender, age, computer comfort level, subject area comfort level, and average grade in subject area were entered as covariates. Total learning performance (all four 
categories) was significantly higher when student worked on WBLTs individually vs. in pairs ( $p$ $<.05)$. The effective size for this difference was considered small according to Cohen (1988, 1992). Changes in learning performance were significantly higher for the remembering knowledge area $(p<.001)$ when WBLTs were used individually vs. when they were used in pairs. The effect size for this difference, based on Cohen's d, is considered large (Cohen, 1988, 1992). Changes in understanding and application knowledge areas showed no significant differences with respect to collaboration (Table 4).

\section{Problems in Technology}

Before analyzing the impact of technological problems, it is important to note that major software and hardware problems occurred infrequently. Only five percent of all classes that used WBLTs experienced major technological difficulties.

\section{Hardware}

A MANOVA was run for hardware problems (none/minor vs. major) and the three student attitude constructs. Gender, age, computer comfort level, subject area comfort level, and average grade in subject area were entered as covariates. Hotelling's T was significant $(p<.001)$, so independent comparisons of WBLT quality constructs were analyzed. Student ratings of learning value $(p<.005)$ and design $(p<.001)$ for WBLTs were significantly higher when fewer or no hardware problems were experienced while using WBLTs. The effect sizes for these differences based on Cohen's d are considered small to moderate (Cohen, 1988, 1992) (Table 5). There were no significant differences in student attitudes toward engagement with respect to magnitude of hardware problems experienced.

An ANCOVA was used to assess learning performance as a function of hardware problems observed. Total learning performance was used because the sample size was too small to assess all four learning performance categories. Gender, age, computer comfort level, subject area comfort level, and average grade in subject area were entered as covariates. Total learning performance was not significantly different for the no/minor vs. major hardware problem conditions.

Table 5: Student Attitudes and Learning Performance as a Function of Hardware Problems

\begin{tabular}{|c|c|c|c|c|}
\hline & $\begin{array}{c}\text { None or Minor } \\
M(S D)\end{array}$ & $\begin{array}{l}\text { Major } \\
M(S D)\end{array}$ & $F$ & $\begin{array}{l}\text { Effect Size } \\
\text { Cohen's d }\end{array}$ \\
\hline \multicolumn{5}{|l|}{ Attitudes } \\
\hline Learning & $25.6(6.0)$ & $(5.9)$ & $7.0 *$ & 0.45 \\
\hline Design & $21.7 \quad(4.0)$ & $18.8 \quad(4.0)$ & $17.3 * *$ & 0.73 \\
\hline Engagement & $19.8 \quad(5.1)$ & $19.1 \quad(5.1)$ & $0.7 \mathrm{~ns}$ & --- \\
\hline
\end{tabular}

Learning Performance

(\% Change)

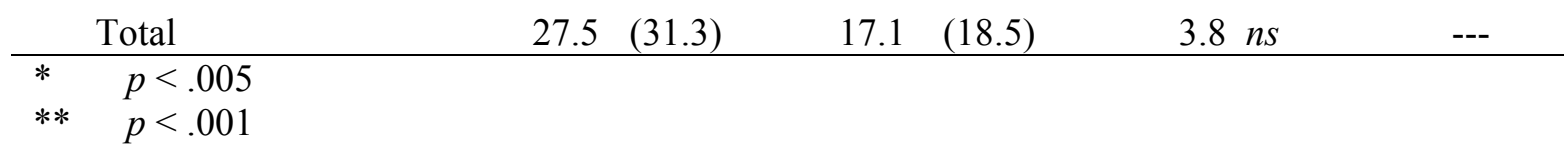

\section{Software}

A MANOVA was run for software problems (none/minor vs. major) and the three student attitude constructs. Gender, age, computer comfort level, subject area comfort level, and average grade in subject area were entered as covariates. Hotelling's T was significant $(p<.001)$, so independent 
comparisons of WBLT quality constructs were done. Student ratings of learning value $(p<.05)$ and engagement $(p<.005)$ for WBLTs were significantly lower when major software problems were experienced while using WBLTs. The effect sizes for these differences based on Cohen's d are considered small to moderate (Cohen, 1988, 1992) (Table 6). There were no significant differences in student attitudes toward WBLT design between none/minor vs. major software problem categories.

An ANCOVA was used to assess learning performance as a function of software problems observed. Total learning performance was used because the sample size was too small to assess all four learning performance categories. Gender, age, computer comfort level, subject area comfort level, and average grade in subject area were entered as covariates. Total learning performance was significantly lower $(p<.05)$ when major as opposed to no/minor software problems were experienced. The effect size for this difference based on Cohen's d is considered moderate (Cohen, 1988, 1992) (Table 6).

Table 6: Student Attitudes and Learning Performance as a Function of Software Problems

\begin{tabular}{|c|c|c|c|c|c|}
\hline & $\begin{array}{l}\text { None or Minor } \\
\text { M (SD) }\end{array}$ & $M a$ & $\begin{array}{l}\text { jor } \\
\text { SD) }\end{array}$ & $\boldsymbol{F}$ & $\begin{array}{l}\text { Effect Size } \\
\text { Cohen's d }\end{array}$ \\
\hline & $M(S D)$ & $M$ & $(S D)$ & & \\
\hline \multicolumn{6}{|l|}{ Perceptions of } \\
\hline Learning & $25.6 \quad(5.9)$ & 21.8 & $(5.9)$ & $5.9 *$ & 0.64 \\
\hline Design & $21.6 \quad(4.0)$ & 20.2 & $(4.0)$ & $3.2 n s$ & --- \\
\hline Engagement & $19.9 \quad(5.1)$ & 17.1 & $(5.0)$ & $8.2 * *$ & 0.56 \\
\hline \multicolumn{6}{|c|}{$\begin{array}{l}\text { Learning Performance } \\
\qquad(\% \text { Change })\end{array}$} \\
\hline Total & $27.4 \quad(30.4)$ & 14.4 & $(30.9)$ & $4.6 *$ & 0.42 \\
\hline
\end{tabular}

\section{Discussion}

The purpose of this study was to explore the influence of context on student attitudes toward WBLTs and learning performance. Five contextual variables were assessed including subject area, grade level, lesson plan format, collaboration, and technology-based problems. The results for each of these variables will be discussed in turn.

\section{Subject Area (Math vs. Science)}

Students who used science-based WBLTs in this study rated perceived learning, design, and engagement significantly higher than students who used math-based WBLTs. This finding was also reported by Kay \& Knaack (2008b). One possible explanation for this result is that students simply like science better than mathematics; however, subject area comfort level was accounted for as a covariate in the analysis. Kay \& Knaack (2008b) suggest that meaningful context and rich multimedia lead to more positive student attitudes toward WBLTs. Student attitudes toward science-based WBLTs may be enhanced because these WBLTs provide more meaningful context and richer visuals than the math-based WBLTs. Twelve of thirteen science-based WBLTs used in this study offered rich context and/or hands on participation in real world tasks whereas eight of the nine math-based WBLTs focused solely on the concept being taught without a real-world connection. 
One could argue that differences between science- and math-based WBLTs was influenced by the qualities of the tools used, not subject area. In other words, if math-based WBLTs were presented in a richer context with more enticing visuals, they might be just as popular as their science-based counterparts. On the other hand, mathematics at the middle and secondary school level may include concepts that are more routinely de-contextualized than those concepts learned in science. For example, in this study, sample concepts for mathematics included adding and subtracting integers, probability with coin tossing, graphing co-ordinates, and line of best fit. It is challenging to find real world meaning for these concepts, particularly for younger students. On the other hand, science-based concepts in this study included building bridges, creating electrical circuits, space stations, and lightening. These topics appear to be more grounded in the real world.

It is worth noting that total learning performance was significantly higher when science-based as opposed to math-based WBLTs were used, a finding also noted by Kay \& Knaack (2008b). This effect may have been partially influenced by positive attitudes students had toward science-based WBLTs. An analysis of individual knowledge areas, though, revealed that the only category showing a significant difference was analysis. Students who used science-based WBLTs improved significantly more when analytic knowledge was tested. It is conceivable, that the interactive, constructive qualities of many of the science-based WBLTs versus the more passive, direct instructions of the math-based WBLTs may have contributed to significant gains in higher level knowledge areas. Since this is a first study examining performance using Bloom's revised taxonomy (Anderson \& Krathwhol, 2001), more research is needed to establish whether specific knowledge categories such as remembering, understanding, application, and analysis are differentially impacted by subject area.

\section{Grade Level (Middle vs. Secondary School)}

Secondary school students in this study rated WBLTs significantly higher than middle school students with respect to learning, design, and engagement. These findings are consistent with previous research (e.g., Kay \& Knaack, 2007b, 2008a). One possible explanation may stem from past studies suggesting that older students have different expectations than younger students when using computers in the classroom (e.g., Colley, 2003; Colley \& Comber, 2003; Comber et al., 1997). Older students may be looking for a straight-forward, easy-to-use tool that will help them learn. They are not expecting bells and whistles, so the rather conservative, but useful WBLTs used in this study meet their expectations and are rated highly. One the other hand, younger middle school students might want entertainment and excitement. Most WBLTs in this study offer good visual supports but are not designed to entertain; therefore middle school students may rate them lower because they are not meeting expectations.

Grade level also had a significant impact on learning performance in favour of older students. According to Cohen $(1998,1992)$, the size of effect for all four learning performance categories was moderate to large. One possible explanation for the impact of grade on learning performance might be to related student expectations and range of cognitive skills required to use a WBLT, including reading instructions, writing down results, interpreting and digesting "what-if" scenarios, and working independently. Younger students, expecting to be entertained, might be surprised and overwhelmed by how much effort is required to learn with WBLTs. Kirschner et al. (2006) note younger students may need more direct scaffolding or instruction when learning new concepts. The challenge of learning independently with a WBLT and acquiring new concepts may cognitively overload middle school students and undermine learning.

Qualitative research in the form of interviews or focus groups would be helpful in trying to understand the differential expectations of students based on grade level and how these expectations might influence subsequent learning performance. 


\section{Lesson Plan Format (Teacher-led vs. Student-Based)}

In this study, student attitudes toward WBLTs and learning performance were significantly higher for teacher-led as opposed to student-based lesson plans. The findings cannot be attributed to gender, age, computer comfort, subject comfort, average grade because these variables were entered as covariates in the analysis. The results support the notion that students in this study, at an average age of 13 years old, needed more direct instruction and/or and support when WBLTs are used (Kirschner et al., 2006). Teacher-guidance may be more effective for young adolescents acquiring a preliminary understanding of basic concepts.

\section{Collaboration (Pairs vs. Individual Use)}

There were no significant differences with respect to attitudes toward WBLTs and whether students worked alone or in pairs. However, students who worked individually significantly outperformed students who worked in pairs, particularly for the category of remembering. At first glance, these findings are somewhat counter intuitive, given the extensive research supporting the extensive benefits of collaboration (e.g., Johnson \& Johnson, 1994, 1998; Kagan, 1997; Sharon, 1999). The precise details of how students collaborated were not recorded and it is possible that one or more of the essential conditions for successful co-operative learning (Johnson \& Johnson, 1994) were not met. It is also possible that working with peers may have been more of a distraction than a benefit, especially with younger students and insufficient scaffolding. More research is needed documenting the quality of collaboration and the use of WBLTs as well as the extent to which students could inhibit each others' progress.

\section{Technology-Based Problems (Hardware and Software)}

When major hardware problems were experienced, student attitudes toward learning and design were significantly lower BUT learning performance was unaffected. Major software problems were associated with significantly lower student attitudes toward WBLTs and reduced learning performance. These results are not unexpected. Because WBLTs are, to a large extent, hardware and software dependent, major technological challenges are likely to inhibit learning. The important finding is that hardware and software problems were experienced by only five percent of the total sample. Even though technology-based problems can have a negative impact on student perceptions and learning performance, they did not occur often, therefore the overall effect of this contextual variable is limited.

\section{Educational Implications}

This study is a first attempt to explore the potential impact of context on the use of WBLTs, so strong recommendations for educators would be premature. However, the results suggest that there are several factors that teachers should be cognizant of when they plan and implement WBLT-based lessons.

Science-based WBLTs appear to be more attractive to students than math-based WBLTs. It is speculated that the rich, meaningful context of science is more appealing than the decontextualized presentation used with mathematics. Teachers may have to supplement mathbased WBLTs with added materials that build interest and meaning.

Teacher-led lessons may work better for younger students or for teaching fundamental concepts because of potential cognitive overload. Students may have difficulty guiding their own learning, using a new WBLT, and learning a set of new concepts simultaneously. Teacher guidance might provide the necessary scaffolding and focus needed for students who are not yet able to guide their own learning. 
If students are collaborating while using WBLTs, it would be prudent to ensure that key elements (face-to-face interaction, individual accountability, social skills, and group processing) outlined by Johnson \& Johnson $(1994,1998)$ are present. Otherwise students might distract each other, thereby inhibiting performance.

Finally, major hardware and software problems can inhibit the acceptance of WBLTs, and to a lesser extent learning performance, but fortunately these kind of problems are rare. Teachers need not worry excessively about the impact of technology-based challenges when WBLTs are used.

\section{Caveats \& Future Research}

Considerable attention was directed toward method in this study. Well tested, reliable, valid, and comprehensive measurement tools were used to assess student perceptions and learning performance for a relatively wide range of systematically selected WBLTs. Because the exploration of context-based variables and the use of WBLTs is new, more research is needed to establish consistency and to address unanswered questions.

It is critical to note that the results of this study are correlational. One cannot assume that the impact of any of the contextual variables actually causes student perceptions or learning performance to change, even though factors such as age, computer ability, and subject areas knowledge were entered as covariates. Experimental research is rare in education, so direct cause and effect relationships are hard to ascertain. However, one promising new direction in future research would be to collect detailed qualitative data in the form of interviews, focus groups, and/or open ended questions to help explore why certain differences exist.

Regarding specific contextual variables assessed in the current study, several changes could be made to gather more useful information. For example, a wider range of subject areas could be tested to assess the impact of content. As well, WBLTs could be assessed in more detail to determine the impact of a meaningful context on student learning experiences. Regarding lesson plan format, types of scaffolding could be manipulated to examine how much support is required for successful learning and whether that required support varies as a function of grade level. With respect to collaboration, clearer guidelines could be provided to students (see Johnson \& Johnson, 1994, 1998) to determine whether working in small groups can be an effective teaching approach when using WBLTs.

One final suggestion would be to record think-aloud data while students are actually using the WBLTs. Essentially, the think-aloud procedure offers a window into the internal talk of a subject while he/she is learning. Ericsson \& Simon (1980), in a detailed critique of the technique conclude that "verbal reports, elicited with care and interpreted with full understanding of the circumstances under which they were obtained, are a valuable and thoroughly reliable source of information about cognitive processes" (pp. 247).

\section{Summary}

The current study examined the influence of five context-based variables (subject area, grade level, lesson plan format, collaboration, and technology-based problems) on student attitudes toward WBLTs and learning performance. Science-based WBLTs, higher grade levels, teacher-led lessons, and the absence of major technology-based problems were associated with significantly higher attitudes toward WBLT learning, design, and engagement quality. The presence or absence of collaboration had no impact on student attitudes toward WBLTs. Science-based WBLTs, higher grade levels, teacher-led lessons, working alone, and the absence of software problems were associated with significantly higher learning performance. It is reasonable to conclude that the context of a WBLT learning environment can have a significant impact on student attitudes and learning. 


\section{References}

Akpinar, Y., \& Bal, V. (2006). Student tools supported by collaboratively authored tasks: The case of work learning unit. Journal of Interactive Learning Research, 17(2), 101-119.

Anderson, L. W., \& Krathwohl, D. R. (Eds.). (2001). A taxonomy for learning, teaching, and assessing: A Revision of Bloom's taxonomy of educational objectives. New York: Longman.

Bartlett, A. (2002). Preparing preservice teachers to implement performance assessment and technology through electronic portfolios. Action in Teacher Education, 24(1), 90-97.

Bower, M. (2005). Online assessment feedback: Competitive, individualistic, or...preferred form! Journal of Computers in Mathematics and Science Teaching, 24(2), 121-147.

Bransford, J. D., Brown, A. L., \& Cocking, R. R. (Eds.). (2000). How people learn. Washington, DC: National Academy Press.

Bruner, J. (1986). Actual minds, possible worlds. Cambridge, MA: Harvard University Press.

Bullock, D. (2004). Moving from theory to practice: An examination of the factors that preservice teachers encounter as the attempt to gain experience teaching with technology during field placement experiences. Journal of Technology and Teacher Education, 12(2), 211-237.

Cohen, J. (1988). Statistical power analysis for the behavioural sciences (2nd ed.). New York: Academic Press.

Cohen, J. (1992). A power primer. Psychological Bulletin, 112(1), 155-159. doi: 10.1037/00332909.112.1.155

Colley, A. (2003). Gender differences in adolescents' perceptions of the best and worst aspects of computing at school. Computers in Human Behaviour, 19(6) 673-682. doi:10.1016/S0747-5632(03)00022-0

Colley, A., \& Comber, C. (2001). Age and gender differences in computer use and attitudes among secondary school students: What has changed? Educational Research, 45(2), 155-165. doi: $10.1080 / 0013188032000103235$

Comber, C., Colley, A., Hargreaves, D. J., \& Dorn, L. (1997). The effects of age, gender and computer experience upon computer attitudes. Educational Research, 39(2), 123-133. doi: $10.1080 / 0013188970390201$

Compton, V., \& Harwood, C. (2003). Enhancing technological practice: An assessment framework for technology education in New Zealand. International Journal of Technology and Design Education, $13(1), 1-26$.

Cronbach, L. J., \& Snow, R. E. (1977). Aptitudes and instructional methods: A handbook for research on interactions. New York: Irvington.

De Salas, K., \& Ellis, L. (2006). The development and implementation of learning objects in a higher education. Interdisciplinary Journal of E-Learning and Learning Objects, 2006 (2), 1-22. Retrieved from http://www.ijello.org/Volume2/v2p001-022deSalas.pdf

Docherty, C., Hoy, D., Topp, H., \& Trinder, K. (2005). E-Learning techniques supporting problem based learning in clinical simulation. International Journal of Medical Informatics, 74(7-8), 527-533. doi:10.1016/j.ijmedinf.2005.03.00

Doering, A., Hughes, J. \& Huffman, D. (2003). Preservice teachers: Are we thinking with technology? Journal of Research on Technology in Education, 35(3), 342-361.

Eifler, K. Greene, T., \& Carroll, J. (2001). Walking the talk is tough: From a single technology course to infusion. The Educational Forum, 65(4), 366-375. doi: 10.1080/00131720108984518

Ericsson, K. A., \& Simon, H. A. (1980). Verbal reports as data. Psychological Review, 87(3), 215251. 
Haughey, M., \& Muirhead, B. (2005). Evaluating learning objects for schools. Australasian Journal of Educational Technology, 21(4), 470-490. Retrieved from http://www.ascilite.org.au/ajet/ajet21/haughey.html

Johnson, D. W., \& Johnson, R. T. (1994). An overview of cooperative learning. In J. S. Thousand, R. A. Villa, \& A. I. Nevin (Eds.), Creativity and collaborative learning: A practical guide to empowering students and teachers (pp 31-44). Baltimore, MD: Brookes.

Johnson, D. W., \& Johnson, R. T. (1998). Learning together and alone. Cooperation, competition, and individualization (5th ed.). Englewood Cliffs, NJ: Prentice-Hall.

Kagan, S. (1997). Cooperative learning (2nd ed.). San Jose Capistrano, CA: Resources for Teachers.

Kay, R. H. (2009). Understanding factors that influence of the effectiveness of learning objects in secondary school classrooms. In L. T. W. Hin \& R. Subramaniam (Eds.), Handbook of research on new media literacy at the K-12 level: Issues and challenges (pp. 419-435). Hershey, PA: Information Science Reference.

Kay, R. H. (2011). Web-based learning tools used in contextual differences study. Retrieved from http://faculty.uoit.ca/kay/res/context_diff/context.html

Kay, R. H., \& Knaack, L. (2007a). Evaluating the learning in learning objects. Open Learning, 22(1), 5-28. doi: 10.1080/02680510601100135

Kay, R. H., \& Knaack, L. (2007b). Evaluating the use of learning objects for secondary school science. Journal of Computers in Mathematics and Science Teaching, 26(4), 261-289.

Kay, R. H., \& Knaack, L. (2008a). An examination of the impact of learning objects in secondary school. Journal of Computer Assisted Learning, 24(6) 447-461.

Kay, R. H., \& Knaack, L. (2008b). A formative analysis of individual differences in the effectiveness of learning objects in secondary school. Computers \& Education, 51(3), 1304-1320. doi: 10.1016/j.compedu.2008.01.001

Kay. R. H., \& Knaack, L. (2009). Assessing learning, quality and engagement in learning objects: The learning object evaluation scale for students (LOES-S). Education Technology Research and Development, 57(2), 147-168.

Kay. R. H., Knaack, L., \& Muirhead, B. (2009). A formative analysis of instructional strategies for using learning objects. Journal of Interactive Learning Research, 20(2), 295-315.

Kay, R. H., Knaack, L., \& Petrarca, D. (2009). Exploring teacher perceptions of web-based learning tools. Interdisciplinary Journal of E-Learning and Learning Objects, 5, 27-50. Available at http://ijklo.org/Volume5/IJELLOv5p027-050Kay649.pdf

Kong, S. C., \& Kwok, L. F. (2005). A cognitive tool for teaching the addition/subtraction of common fractions: A model of affordances. Computers and Education, 45(2), 245-265. doi:10.1016/j.compedu.2004.12.002

Kirschner, P. A., Sweller, J., \& Clark, R. E. (2006). Why minimal guidance during instruction does not work: An analysis of the failure of constructivist, discovery, problem-based, experiential, and inquirybased teaching. Educational Psychologist, 41(2), 75-86. doi: 10.1207/s15326985ep4102_1

Lim, C. P., Lee, S. L., \& Richards, C. (2006). Developing interactive learning objects for a computing mathematics models. International Journal on E-Learning, 5(2), 221-244.

Liu, M., \& Bera, S. (2005). An analysis of cognitive tool use patterns in a hypermedia learning environment. Educational Technology, Research and Development, 53(1), 5-21. doi: 10.1007/BF02504854

Mayer, R. (2004). Should there be a three-strikes rule against pure discovery learning? The case for guided methods of instruction. American Psychologist, 59(1), 14-19. doi: 10.1037/0003-066X.59.1.1

Nurmi, S., \& Jaakkola, T. (2006). Effectiveness of learning objects in various instructional settings. Learning, Media, and Technology, 31(3), 233-247. doi: 10.1080/17439880600893283 
Organization for Economic Co-operation and Development (OECD). (2006). Education at a glance. Retrieved from http://mt.educarchile.cl/MT/jijbrunner/archives/libros/OECD_Gl2006/Edu_glance2006.pdf

Papert, S. (1980). Mindstorms: Children, computers, and powerful ideas. New York: Basic Books.

Russell, M., Bebell, D., O’Dwyer, L., \& O'Connor, K. (2003). Examining teacher technology use: Implications for preservice and inservice teacher preparation. Journal of Teacher Education, 54(4), 297-310. doi: $10.1177 / 0022487103255985$

Schoner, V., Buzza, D., Harrigan, K., \& Strampel, K. (2005). Learning objects in use: 'Lite' assessment for field studies. Journal of Online Learning and Teaching, 1(1), 1-18. Retrieved from http://jolt.merlot.org/documents/voll_no1_schoner_001.pdf

Sharon, S. (Ed.). (1999). Handbook of cooperative learning methods. Westport, CT: Praeger.

Steffe, L., \& Gale, J. (Eds.). (1995). Constructivism in education. Hillsdale, NJ: Lawrence Erlbaum Associates, Inc.

Strudler, N., \& Wetzel, L. (1999) Lessons from exemplary colleges of education: Factors affecting technology integration in preservice programs. Educational Technology Research and Development, 47(4), 63-81. doi: 10.1007/BF02299598

Sweller, J. (1988). Cognitive load during problem solving: Effects on learning. Cognitive Science, 12, 257 285.

Vannatta, R. A., \& Beyerbach, B. (2000). Facilitating a constructivist vision of technology integration among education faculty and preservice teachers. Journal of Research on Computing in Education, 33(2), 132-148.

Van Merrienboer, J. J. G., \& Ayres, P. (2005). Research on cognitive load theory and its design implications for e-learning. ETR\&D, 53(3), 1042-1629. doi: 10.1007/BF02504793

Vygotsky, L.S. (1978). Mind in society. Cambridge, M.A.: Harvard University Press.

Wepner, S. B., Ziomek, N., \& Tao L. (2003). Three teacher educators' perspectives about the shifting responsibilities of infusing technology into the curriculum. Action in Teacher Education, 24(4), 53-63. 


\section{Appendix - WBLT Evaluation Scale}

\section{Learning}

1. Working with the learning object helped me learn.

2. The feedback from the learning object helped me learn.

3. The graphics and animations from the learning object helped me learn.

4. The learning object helped teach me a new concept.

5. Overall, the learning object helped me learn.

\section{Design}

6. The help features in the learning object were useful.

7. The instructions in the learning object were easy to follow.

8. The learning object was easy to use.

9. The learning object was well organized.

\section{Engagement}

10. I liked the overall theme of the learning object.

11. I found the learning object engaging.

12. The learning object made learning fun.

13. I would like to use the learning object again.

\section{All scale items used the following 7-point Likert scale}

$1=$ Strongly Disagree

$2=$ Disagree

$3=$ Somewhat Disagree

$4=$ Neutral

$5=$ Somewhat Agree

$6=$ Agree

$7=$ Strongly Agree

\section{Biography}

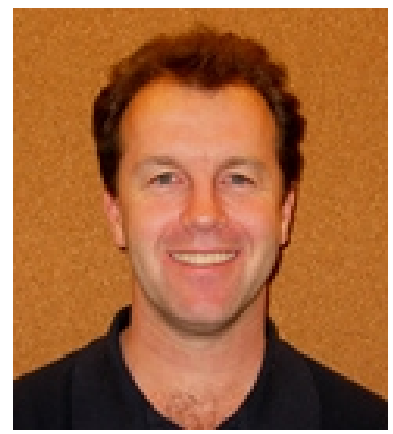

Robin Kay, Ph.D. is an Associate Professor in the Faculty of Education at the University of Ontario Institute of Technology. He has published over 50 articles and chapters in the area of computers in education, presented numerous papers at 15 international conferences, refereed five prominent computer education journals, and taught computers, mathematics, and technology for over 20 years. Current projects include research on laptop use in teacher education, classroom response systems, web-based learning tools, and factors that influence how students learn with technology. 